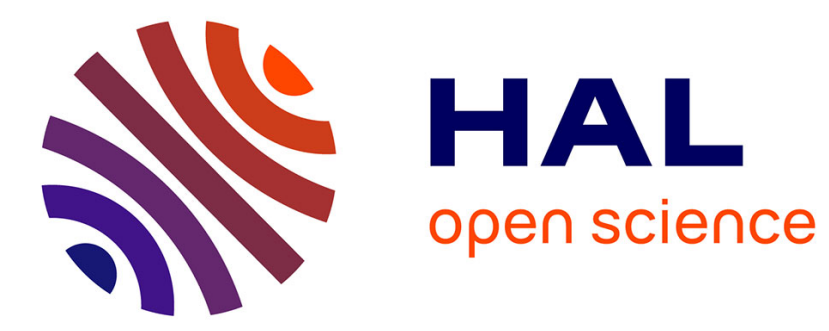

\title{
Midair transformations of aerosols
}

\author{
Manuel F. Ruiz-Lopez
}

\section{To cite this version:}

Manuel F. Ruiz-Lopez. Midair transformations of aerosols. Science, 2021, 374 (6568), pp.686-687. 10.1126/science.abl8914 . hal-03419372

\section{HAL Id: hal-03419372 \\ https://hal.science/hal-03419372}

Submitted on 8 Nov 2021

HAL is a multi-disciplinary open access archive for the deposit and dissemination of scientific research documents, whether they are published or not. The documents may come from teaching and research institutions in France or abroad, or from public or private research centers.
L'archive ouverte pluridisciplinaire HAL, est destinée au dépôt et à la diffusion de documents scientifiques de niveau recherche, publiés ou non, émanant des établissements d'enseignement et de recherche français ou étrangers, des laboratoires publics ou privés. 


\title{
Midair transformations of aerosols
}

Manuel F. Ruiz-Lopez

Science, 374, 686-687 (2021)

DOI:10.1126/science.abl8914

Note that the title of the published version differs from the title of the accepted version. The Figure and parts of the main text have been edited and differ also from those in the accepted version.

\section{Unfavorable chemical reactions go spontaneously at the surface of aerosols}

\author{
Manuel F. Ruiz-Lopez \\ Laboratoire de Physique et Chimie Théoriques, UMR CNRS 7019, University of Lorraine, CNRS, BP 70239, 54506 \\ Vandoeuvre-lès-Nancy, France
}

Atmospheric aerosols are tiny solid or liquid particles suspended in the air that have major impact on climate, air quality, outdoor visibility and human health. Aerosols are directly emitted by natural sources and human activities but can also be formed from gaseous precursors. Therefore, their composition is extremely variable, and common aerosols are composed of sea salt, dust, soot, organic carbon, ice, water droplets, and complex mixtures of them. On the aerosol surface, water vapor and other gaseous compounds adsorb and react to form new compounds that have the capacity to influence the atmospheric chemical cycles. $(1,2)$ However, little is known about this chemistry despite the importance it has for improving current air quality and climate models. On page $X$ of this issue, Kong et al.(3) describe an aerosol surface-driven reaction of great atmospheric relevance, presenting also interesting potential industrial applications. They have discovered that ammonium sulfate crystals exposed to water vapor spontaneously form elemental sulfur and nitrogen gas on their surface, a chemical transformation that is known to be unfavorable in conventional aqueous solution.

Ammonium sulfate is a major component of continental aerosols and plays a role on cirrus cloud formation.(4) Although natural sources can produce ammonium sulfate aerosols, human activities are the main cause. In the troposphere, ammonia, emitted from agriculture, combines to sulfuric acid (a main component of acid rain) generated by sulfur dioxide emissions from fossil fuels combustion. The resulting ammonium sulfate salt may consist of aqueous solutions or crystallized particles, depending on air humidity and temperature. Kong et al. have studied the behavior of ammonium sulfate crystals exposed to varying concentrations of water vapor with an experimental technique called ambient pressure X-ray photoelectron spectroscopy. It allows measuring the binding energy of inner electrons in sulfur and nitrogen atoms on the crystal surface, which is a signature of the compound these atoms are involved in. In dry conditions, only the expected signatures for sulfate and ammonium ions are observed. However, when the relative humidity increases (up to 48\%), the salt partially dilutes over the surface, and an unexpected chemistry occurs producing elemental sulfur, bisulfide ions, nitrous acid and ammonia. If the relative humidity is further increased to the deliquescence threshold of $78 \%$, when the salt completely dissolves in water and the system turns to an aqueous solution, there is a transient period during which elemental sulfur dominates the spectra and nitrogen signals vanish. Progressively, however, sulfate, ammonium and ammonia signals appear again, and a new steady state is reached. The assignment of the signals and important aspects of the underlying transformation mechanisms have been guided and supported by quantum chemistry and molecular dynamics calculations. 
The authors have concluded that spontaneous sulfate-reducing ammonium oxidation (SRAO) reaction is at play in the limited hydration conditions prevailing during aqueous dilution of the salt on the surface. However, SRAO does not happen in dry conditions or when the salt is completely dissolved. The final products of the SRAO reaction are elemental sulfur and nitrogen gas. The latter is not detected in the experiments carried out by Kong et al. likely because it has a low water solubility and escapes to the gas phase as it is being formed. The ease with which the SRAO process occurs in the aqueous layer at the vapor-crystal interface is remarkable because it is an unfavorable reaction that does not take place spontaneously under ordinary conditions. For instance, biocatalysts must be used in current wastewater treatment applications.

The atmospheric implications of these findings are at least twofold. First, they suggest that in humid air highly oxidized sulfur compounds (such as sulfate) may spontaneously be reduced, i. e. converted to less oxidized compounds (elemental sulfur, bisulfide). This new chemistry is unexpected in the atmosphere, which is an oxidizing medium, and is likely to shape our current understanding of the sulfur cycle. Second, nitrous acid has been identified as an intermediate product, which is a key atmospheric precursor of the extremely reactive hydroxyl radical, the so-called "atmosphere's detergent", whose concentration is underestimated by existing models. Thus, SRAO reactions on sulfate ammonium aerosols could represent a possible additional source of this species.

The broader significance of the work relates to the "on water catalysis" phenomenon,(5) consisting in the rate acceleration of chemical reactions at water surfaces (e.g. water droplets, thin water films) and aqueous interfaces (e.g. oil-in-water microemulsions).(6) Though still incompletely understood, this phenomenon is illustrated by several chemical $(7)$ and photochemical $(8,9)$ processes on atmospheric aqueous aerosols. Exciting results have also been reported in the field of prebiotic chemistry since the interfaces formed by water droplets coated with an organic film share similarities with cell membranes, and could have favored the processes that led to the origin of life on Earth.(10) Moreover, chemistry "on water" has raised increasing interest for applications in organic synthesis using dispersed aqueous systems(11) or sprayed aqueous microdroplets(12), for instance. Difficult reactions "in water" have been found to proceed easily "on water", the spontaneous oxidation of water to hydrogen peroxide being an outstanding example.(13) These results are extremely interesting for industrial applications because they open avenues for the development of efficient synthetic approaches in green chemistry, avoiding the use of organic solvents.

Why some unfavorable chemical reactions are boosted at aqueous interfaces? There is no simple answer to this question but it has been shown that fundamental molecular properties such as the oxidation potential(14) or the acidity(15) change when the species it adsorbed at an aqueous interface. The local electric fields associated to the structural asymmetry of the interface are probably key in explaining such modifications. The alignment and confinement of the reagents, or the large surface to volume ratio exhibited by microscopic systems are for sure other important factors that need to be taken into account for understanding the "on water catalysis" effect. These issues are being intensely debated in the literature(6) and future research should aim at clarifying their respective contribution. In this regard, the parallel study of selected reactions with different experimental techniques and elaborated theoretical molecular simulations would be most valuable.

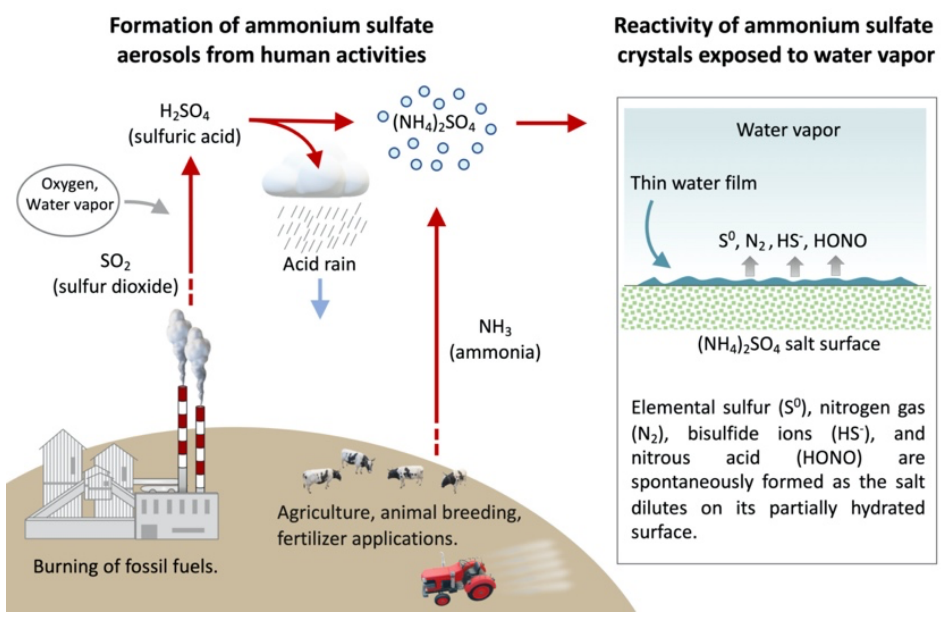


1. A. R. Ravishankara, Science 276, 1058-1065 (1997).

2. M. O. Andreae, P. J. Crutzen, Science 276, 1052-1058 (1997).

3. X. Kong, D. Castarède, E. S. Thomson, A. Boucly, L. Artiglia, M. Ammann, I. Gladich, J. B. C. Pettersson, Science Vol, XXX-YYY (2021).

4. J. P. D. Abbatt, S. Benz, D. J. Cziczo, Z. Kanji, U. Lohmann, O. Mohler, Science 313, 1770-1773 (2006).

5. S. Narayan, J. Muldoon, M. G. Finn, V. V. Fokin, H. C. Kolb, K. B. Sharpless, Angew. Chem. Int. Ed. 44, 3275-3279 (2005).

6. M. F. Ruiz-Lopez, J. S. Francisco, M. T. C. Martins-Costa, J. M. Anglada, Nat. Rev. Chem. 4, 459-475 (2020).

7. E. M. Knipping, M. J. Lakin, K. L. Foster, P. Jungwirth, D. J. Tobias, R. B. Gerber, D. Dabdub, B. J. Finlayson-Pitts, Science 288, 301-306 (2000).

8. C. George, M. Ammann, B. D'Anna, D. Donaldson, S. A. Nizkorodov, Chem. Rev. 115, 4218-4258 (2015).

9. J. M. Anglada, M. T. C. Martins-Costa, J. S. Francisco, M. F. Ruiz-López, J. Am. Chem. Soc. 142, $16140-$ 16155 (2020).

10. C. M. Dobson, G. B. Ellison, A. F. Tuck, V. Vaida, Proc. Natl. Acad. Sci. USA 97, 11864-11868 (2000).

11. S. Serrano-Luginbuhl, K. Ruiz-Mirazo, R. Ostaszewski, F. Gallou, P. Walde, Nat. Rev. Chem. 2, 306-327 (2018).

12. X. Yan, R. M. Bain, R. G. Cooks, Angew. Chem. Int. Ed. 55, 12960-12972 (2016).

13. J. K. Lee, K. L. Walker, H. S. Han, J. Kang, F. B. Prinz, R. M. Waymouth, H. G. Nam, R. N. Zare, Proc. Natl. Acad. Sci. USA 116, 19294-19298 (2019).

14. M. T. C. Martins-Costa, J. M. Anglada, J. S. Francisco, M. Ruiz-Lopez, Angew. Chem. Int. Ed. 51, 54135417 (2012).

15. H. Mishra, S. Enami, R. J. Nielsen, L. A. Stewart, M. R. Hoffmann, W. A. Goddard, A. J. Colussi, Proc. Natl. Acad. Sci. USA 109, 18679-18683 (2012). 